cell count $8.6 \times 10^{9} /$, serum IgA $3.15 \mathrm{~g} / 1$ (18 months) and $2.65 \mathrm{~g} / \mathrm{l}$ (20 months), antinuclear antibody titre $1: 80$. There was no IgG or IgM to Epstein-Barr or cytomegalovirus, no urinary light chains, a normal number and proportion of $T$ and $B$ cells, and normal whole blood proliferation to mitogen. Chest radiography and abdominal ultrasound were normal.

The pathogenesis of the paraprotein in our patient is unclear. The adult entity of benign monoclonal gammopathy has not been described in the paediatric population, and previous reports of monoclonal gammopathy in children have consistently associated such gammopathies with serious disease. Additionally, there are no reports of a monoclonal gammopathy as an incidental finding in an otherwise healthy child. In a 10 year review of 4000 highly selected children, $155(3.9 \%)$ were found to have paraproteinaemia. ${ }^{1}$ These children were suffering from primary and secondary immunodeficiency, malignancy, autoimmune disease, asthma, serious infection, and asplastic anaemia. In contrast, none of the 120 healthy paediatric controls used in this study (donors for bone marrow transplantation) had paraproteins identified.

Our case is also unusual in that her paraprotein is of the IgA type, as there are only four reports of IgA monoclonal gammopathy in the paediatric population. Two of these children had a severe combined immunodeficiency, one had an unspecified malignancy, ${ }^{1}$ and the other an unspecified chromosomal disorder. ${ }^{2}$ Of the 155 children with monoclonal gammopathy in the 10 year study previously referred to, no IgA paraproteins were identified.

It is possible this abnormal production of IgA is related to a subtle $\mathrm{T}$ cell dysregulation. Such dysregulation of $\mathrm{T}$ cells has been implicated in another paediatric disorder associated with raised IgA, IgA nephropathy. In this condition abnormal $\mathrm{T}$ cell function and signalling is thought to be responsible for the aberrant $B$ cell activity, where respiratory pathogens or common environmental antigens stimulate excessive production of IgA, in the presence of increased helped $\mathrm{T}$ cell activity ${ }^{3}$ and decreased suppressor T cell numbers. ${ }^{4}$

We are following up this infant, with much interest, for any alteration in her IgA paraprotein or immune function, and for the possible development of disease.

D E CAMPBELL A S KEMP
Department of Immunology,
Royal Children's Hospital,
Parkville, Victoria 3052, Australia

1 Gerritsen E, Vossen J, Van Tol M, Jol Van Der Zijde C, Van Der Weijden-Ragas R, Radl J. Monoclonal Immunol 1989; 9: 296-305.

2 Danon F, Seligmann M. Serum monoclonal immunoglobulins in children. Arch Dis Child 1973; 48: 207-11.

3 Lai KN, Ho RTH, Lai W, Chan CHS, Li PKT Increase of both circulating Th1 and Th2 lymphocyte subsets in IgA nephropathy. Clin Exp phocyte subsets in IgA nephr

4 Sakai $H$, Miyazaki $M$, Endoh $M$, Nomoto $Y$. Increase of IgA specific switch $\mathrm{T}$ cells in patients with $\operatorname{IgA}$ nephropathy. Clin Exp Immunol 1989; 78: 378-82.

\section{Long term follow up to determine the prognostic value of imaging after urinary tract infections}

EDITOR,-I read with interest the two papers by Merrick et al on the prognostic value of imaging in children with urinary tract infections (UTIs). ${ }^{12}$
It would be helpful if the authors could tell us what proportion of the initial cohort of children with UTI, during 1975 to 1990 , underwent initial imaging and later follow up imaging. We have shown that in an area of very good standard for general practice only a small minority of children with UTI had been referred for radiological investigations. ${ }^{3}$ The fact that this 'denominator' figure is not provided casts doubt on how representative their results are. The true natural history and prognostic value of different radiological abnormalities, further UTIs, etc, can only be determined on a large scale, prospective, hospital and community based study.

LYDA JADRESIC

Department of Paediatrics, Gloucestershire Royal Hospital, Great Western Road,
Gloucester GL1 3NN

Merrick MV, Notghi A, Chalmers N, Wilkinson AG, Uttley WS. Long term follow up to deter mine the prognostic value of imaging afte urinary tract infections. Part 1: reflux. Arch Dis Child 1995; 72: 388-92.

2 Merrick MV, Notghi A, Chalmers N, Wilkinson AG, Uttley WS. Long term follow up to determine the prognostic value of imaging after urinary tract infections. Part 2: scarring Arch Dis Child 1995; 72: 393-6.

3 Jadresic L, Cartwright K, Cowie N, Witcombe B, Stevens D. Investigation of urinary tract infection in childhood. BMF 1993; 307: 761-4.

EDITOR,--Merrick et al recommend micturating cystourethrography (MCU) be restricted to females who have not achieved bladder control. ${ }^{1}$ Based on their data that suggest vesicoureteric reflux (VUR) is not a risk factor for progressive renal damage in boys less than 1 year of age, the authors excluded males. ${ }^{2}$ As there is a possibility of type II statistical error with a sample size of only 205 children, basing evaluation strategies on such a small sample size warrants careful scrutiny.

The risk of renal damage due to pyelonephritis is considered greatest in the first few years of life. ${ }^{34}$ The most common indication for antibiotic prophylaxis to prevent pyelonephritis in infancy is the presence of VUR. We are concerned that the recommendation by Merrick et al might restrict the prescription of antibiotic prophylaxis in infant boys and thereby increase the risk of potentially avoidable episodes of pyelonephritis with attendant renal damage.

The indications for MCU and antibiotic prophylaxis are evolving. Since pyelonephritis and renal scarring can develop in infants who do not have VUR, perhaps an episode of pyelonephritis in infancy justifies antibiotic prophylaxis, regardless of the presence or absence of VUR.

WM LANE M ROBSON University of South Carolina School of Medicine, Paediatric Nephrology, The Children's Hospital, Greenville Hospital System, Memorial Medical Office Building, Memorial Medical Office Building, Greenville, SC 29605-4253, USA ROBIN KELLEY Paediatric Infectious Disease,
Greenville Memorial Hospital, Greenville Hospital System, Greenville, SC, USA

1 Merrick MV, Notghi A, Chalmers N, Wilkinson AG, Uttley WS. Long term follow up to determine the prognostic value of imaging after Child 1995; 72: 388-92.

2 Merrick MV, Notghi A, Chalmers N, Wilkinson AG, Uttley WS. Long term follow up to determine the prognostic value of imaging after mine the prognostic value of imaging after
urinary tract infections. Part 2: scarring. Arch Dis Child 1995; 72: 393-6.
3 Berg UG, Johansson SB. Age as a main determinant of renal functional damage in urinary tract infection. Arch Dis Child 1983; 58: 963-9.

4 Jacobson SH, Eklöf O, Eriksson CG, Lins LE, Tidgren B, Winberg J. Development of hypertension and uraemia after pyelonephritis in childhood: 27 year follow-up. BMF 1989; 299:

Dr Uttley comments:

I would like to thank Dr Jadresic for her interest in the two papers by Merrick et al. The vast majority of children referred to the Edinburgh hospitals with UTI, either acutely or after treatment, would have undergone maging of their urinary tract in some form. This has been standard hospital practice and teaching throughout the period of the review. Indeed the need for investigation after a single UTI has been the formal recommendation to undergraduates, postgraduates, and general practitioners throughout. Needless to say we have no information regarding children not referred by their general practitioners and we agree with Dr Jadresic that some patients may not have been referred. Large scale prospective hospital and community based studies are indeed required, and perhaps the impending era of national guidelines and audit will help to answer these thorny questions in the future.

With regard to the letter of Drs Robson and Kelley we do not recommend MCU to be restricted solely to females who have not achieved bladder control. Although it has not emerged as an independent variable for progression of renal disease in young boys, an MCU is clearly an important part of their work-up, particularly after febrile UTI and where abnormalities other than VUR could well be present. However, we do feel the indirect voiding study to be a more sensitive, and a substantially less invasive and traumatic way of assessing the presence or absence of VUR in all children who have achieved bladder control and that this now should be seen as the initial test for reflux.

The data presented reaffirm the importance of reflux as a risk factor for progressive renal damage generally and particularly so when associated with infection.

The fact that VUR did not come out as a risk factor for progressive renal damage in boys under 1 year of age, must be due in part to the fact that this particularly vulnerable group did in general receive appropriate antibiotic prophylaxis. A further issue is that renal damage identified at presentation in these young males will represent renal dysplasia, sometimes profound, and for which evidence of progression was difficult to elucidate.

Overall it would be a pity if debate over appropriate investigation was to overshadow the importance of appropriate clinical follow up and antibiotic treatment and prophylaxis and to that extent we are in total agreement with the final paragraph of Drs Robson and Kelley's letter.

\section{Non-accidental fracture occurring in} hospital

EDITOR,-Recent reports have implied that fractures occurring to infants in hospital are due to natural causes, whereas those occurring out of hospital may be due to non-accidental injury. The inference is that fractures occurring within a place of safety cannot be non-accidental. We report a case of a child who sustained a non-accidental fracture of the left radius and ulnar while in hospital. 